\title{
Evaluating the impact of the product element and logistics service quality on the customer experience in construction Industries
}

\begin{abstract}
Ahmad A-Fadly ${ }^{a^{*}}$
${ }^{a}$ College of Business Administration, Gulf University of Science and Technology, Kuwait

\section{H R O N I C L E}

Article history:

Received April 21, 2020

Received in revised format June

8, 2020

Accepted June 222020

Available online

June 272020

Keywords:

Product element

Logistics service

Customer experience

Construction industry

\section{A B S T R A C T}

The objective of this research was to evaluate the impact of the product element and logistics service quality on the customer experience within construction industries. A questionnaire was developed for data collection based on the gap analysis identified in the literature review. The questionnaire was administered face-to-face to customers associated with the construction industry. A structural model was created and the data were analysed by Structural Equation Modelling using IBM SPSS-AMOS Statistics for Windows version 21. Two aspects of product specialization and four aspects of customer experience were identified as key constructs for customer satisfaction. Product specialization was dependent on product marketing and product attributes. Customer experience was dependent on reputation, confidence, information and expertise. The analysis showed that product specialization and customer experience were major contributors to customer satisfaction. Recommendations using these findings were made for participating construction companies to restructure their business strategies to offer better services vital to customer satisfaction and better business.
\end{abstract}

(C) 2020 by the authors; license Growing Science, Canada.

\section{Introduction}

The reliability of the products and quality of services plays an important role in evaluating the value provided to the customers (Lemon \& Verhoef, 2016). In addition, for the adequate logistics service quality, it is necessary the products and services which are offered to the customers are reliable, hence, the reliability helps the company in improving the service quality. Moreover, the reliability helps the company to emphasise on the promptness and attentiveness in dealing with the complaints and customer experience (Bueno, Weber, Bomfim, \& Kato, 2019). The marketing mix has long been used as a model for driving customer satisfaction. Customer satisfaction is perceived to be the collective summary of customer experiences of the customer-supplier interaction. The supplier in this case being the construction companies. Consequently, construction companies are aware of the importance of understanding customer experiences and finding ways of offering the best experiences. One way to do this has been to employ the marketing mix strategy. However, the role of the marketing mix and its significance on the sustainability of an organization has not been definitive (Mokhtariani, Sebt, \& Davoudpour, 2017). Therefore, studies that focus on the construction industry with an emphasis on the customer experience are needed to establish a basis to foster customer satisfaction and ultimately, repeat business. Customer experience is an important aspect of commercial success through continued business. This customer experience leverages the competitive advantage by increasing the buyer potential of customers (Lemon \& Verhoef, 2016). Hence, a correct understanding of customer experience is vital to create a long-term sustainable advantage for any organization. The characterization of customer experience is thus, pertinent to enable the product (or service) provider to grasp the underlying precepts of what delights the customer. When this experience is overlaid with the marketing mix, in particular the product element, the endeavour to deliver customer expectations become stringent (Al-Debi \& Al-waely, 2015). Thus, the problem statement is: Construction companies do not have an objective understanding of the importance of product mix on customer experience. Driven by

* Corresponding author

E-mail address: alfadly.a@gust.edu.kw (A. A-Fadly)

(C) 2020 by the authors; licensee Growing Science.

doi: $10.5267 /$ j.uscm.2020.7.001 
this context, this study elucidates how the product element of marketing mix affects customer experience leading to customer satisfaction. Until recently, the building industry has experienced an annual average increase of 9 per cent. This growth in the construction sector was driven by optimizing government spending on roads, commercial and residential building projects in the nation (Timetric, 2017). As goods mature, focusing on the full consumer experience becomes increasingly more challenging. When major product quality becomes equivalent, customers place greater importance on the product specialization. Hence, the construction industry needs to recognize this experience. In terms of functionality, accessibility, quality, quantity, availability, customer support, and price, the marketing efforts have traditionally emphasized product performance (Bueno, Weber, Bomfim, \& Kato, 2019). Marketing managers have concentrated on improving customer trust, finding out how customer perceptions originate from a variety of customer-company interactions that raise a purchase reaction. In particular, the impact of the product element on the customer experience is an essential factor in the success of the customer satisfaction (Awan, Arshad, \& Awan, 2015).

This research elucidates the effect of the product element of the marketing mix on the customer experience of construction industries.

\section{Theoretical Background and Hypotheses Development}

\subsection{Construction Industry}

Excellent infrastructure that attracts foreign investors due to a rise in the demand for industrial and residential units and urbanization rates were projected to increase annually by $2.42 \%$ until 2025 (Marketing Research Reports, 2016). Most service companies and construction companies were therefore moving towards a more personal approach by taking into account every individual customer characteristics and expectations (Dudovskiy, 2012). A customer's previous service experience raised the customer's new expectation especially if the construction company had reputable records. Hence, the relationship between the customer experience and the construction company was imperative (Jarkas \& Radosavljevic, 2012).

\subsection{Customer Experience}

Within the marketing mix, customer experience is a central connection between brand and product. Product characteristics affect brand comparability entirely by influencing customer experience of the product features (Sheng \& Thompson, 2012). Customers identify themselves through products with a specific purpose to preserve, communicate and reinforce their selfconceptions. With high self-conceptions, customer satisfaction is affected by the emotional process of involvement (Bueno, Weber, Bomfim, \& Kato, 2019). Customer engagement requires developing familiarity with the business to represent the perception that businesses can deliver goods and services that customers can use to co-develop their own expertise (Lin, 2011).

\subsection{Customer Expectation}

Meeting the expectations of customers can be challenging due to several reasons. First, customers may make impractical demands. While the service delivery endeavours to satisfy the customer, it is necessary to help the customer respectfully discover the impracticability of the demand. Second, customer expectations are ever growing due to the increase in the level of competition. This compels companies to meet demands at a cost to their profit margins. Consequently, from the standpoint of customer expectation, the effect of the customer experience on the service provider and choice of the provider is an important dimension (Tsai, Chang, \& Ho, 2015).

\subsection{Marketing Mix - Product}

Construction companies need to understand the buying decisions of customers for different products. Companies need to anticipate customer needs so that a product is sold without persuasion. This can be accomplished by effective marketing. Marketing is a public and professional mechanism that enables the production and sales of value-add products. Most construction companies commonly use and embrace this concept (Mokhtariani, Sebt, \& Davoudpour, 2017).

The marketing mix consists of variables that facilitate a company to gain the response it wants from the target market. The product represents a key component of the marketing mix, allowing a company to influence product demand. Marketing mix is a critical aspect in all business sectors because of its direct effect on productivity, customer loyalty, and market performance. A good marketing mix can create many advantages for construction firms. Among others, good marketing mix allows viable growth, improved profits sales and client satisfaction leading to improved customer loyalty and reputation. This consequently leads construction companies to realize better businesses with customers (Mahmood, Sebt, \& Davoudpour, 2017). 


\subsection{Customer Satisfaction}

A crucial factor in associating the product traits with brand customer satisfaction is customer experience (Sheng \& Thompson, 2012). Research in customer behaviour shows that brand and customer experiences encourage customer satisfaction. In the mind of the customer, the product brand consists of attachment to the marketing, marketing practices, product attitude and product perception (Fatma, 2014). With customer demands in attitudes, feelings and self-expression, product specialisation and relationship have become an important antecedent to customer satisfaction (Fatma, 2014).

\subsection{Conceptual Model}

Based on the literature review (Section 2.1 to 2.5) above, the following conceptual model was proposed for study in this research. It was postulated that customer satisfaction depends on two dimensions, namely product specialization and customer experience. See Fig. . Product specialization is reflected by marketing and product attributes. The constructs for product specialization was adapted from the literature review (Lin, 2011). Customer experience was reflected by reputation, confidence, information and expertise. The constructs for product specialization were augmented from the authors experience and general perceptions of good customer experience (Tsai, Chang, \& Ho, 2015). The constructs were also deliberated based on the authors extensive experience in the construction industry and stated as the following (alternative) hypotheses and development as objectives to be studied in this research.

1. Product Specialization

H1a: Product Marketing is positively related to Product Specialization

$\mathrm{H} 2 \mathrm{a}$ : Product Attributes is positively related to Product Specialization

H3a: Product Specialization is positively related to Customer Satisfaction

2. Customer Experience

$\mathrm{H} 4 \mathrm{a}$ : Reputation is positively related to Customer Experience

H5a: Confidence is positively related to Customer Experience

H6a: Informed is positively related to Customer Experience

H7a: Expertise is positively related to Customer Experience

H8a: Customer Experience is positively related to Customer Satisfaction

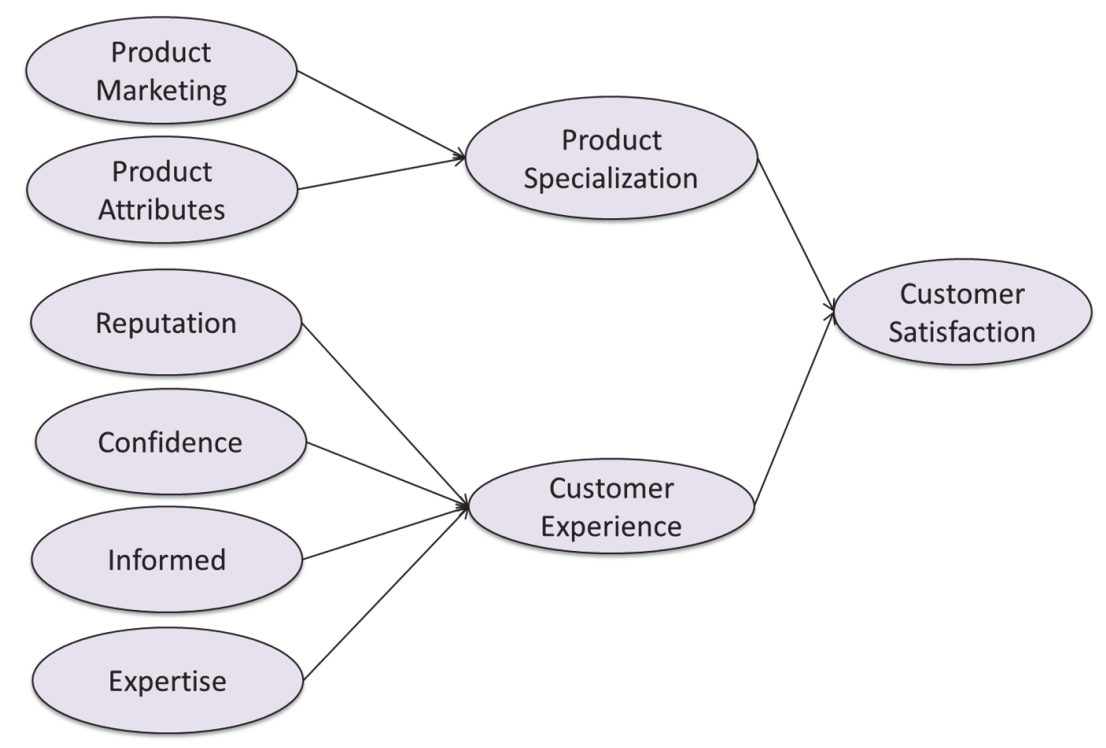

Fig. 1. Conceptual / Full Model.

\section{Research Method}

In this study, the Structural Equation Modelling method was used to conduct causal modelling, path analysis, Exploratory Factor Analysis (EFA) and Confirmatory Factor Analysis (CFA). The analysis was conducted using IBM SPSS-AMOS Statistics for Windows version 21. This method was chosen over other covariance based methods, such as the Partial Least 
Squares method owing to the availability of fit indices that are more easily used for model fit purposes (Hu \& Bentler, 1999).

\subsection{Research Instrument}

The questionnaire development was adapted from the 5-Step model (Radhakrishna, 2007).

Step 1. The research instrument was based on the conceptual framework from the literature review. Two constructs, namely, product marketing and product attributes were used to measure the dimension of product specialization. Similarly, four constructs namely, reputation, confidence, informed and expertise, were used to measure the dimension of customer experience. Both product specialization and customer experience were used to determine customer satisfaction. See Fig. 1.

Step 2. Using nine constructs, a questionnaire was created with 46 items as shown in Table and diagrammatically in Fig. 2. The questionnaire items were used to elucidate perceptions, opinions and behavioural factors that supported the conceptual model.

Table 1

Constructs and Items in Questionnaire

\begin{tabular}{clcc}
\hline No. & Construct & Code & Items \\
\hline 1 & Product Marketing & PM & 6 \\
2 & Product Attributes & PT & 4 \\
3 & Product Specialization & PS & 4 \\
4 & Reputation & RP & 6 \\
5 & Confidence & CN & 5 \\
6 & Informed & EX & 4 \\
7 & Expertise & CE & 7 \\
8 & Customer Experience & SA & 5 \\
9 & Customer Satisfaction & 5 \\
\hline
\end{tabular}

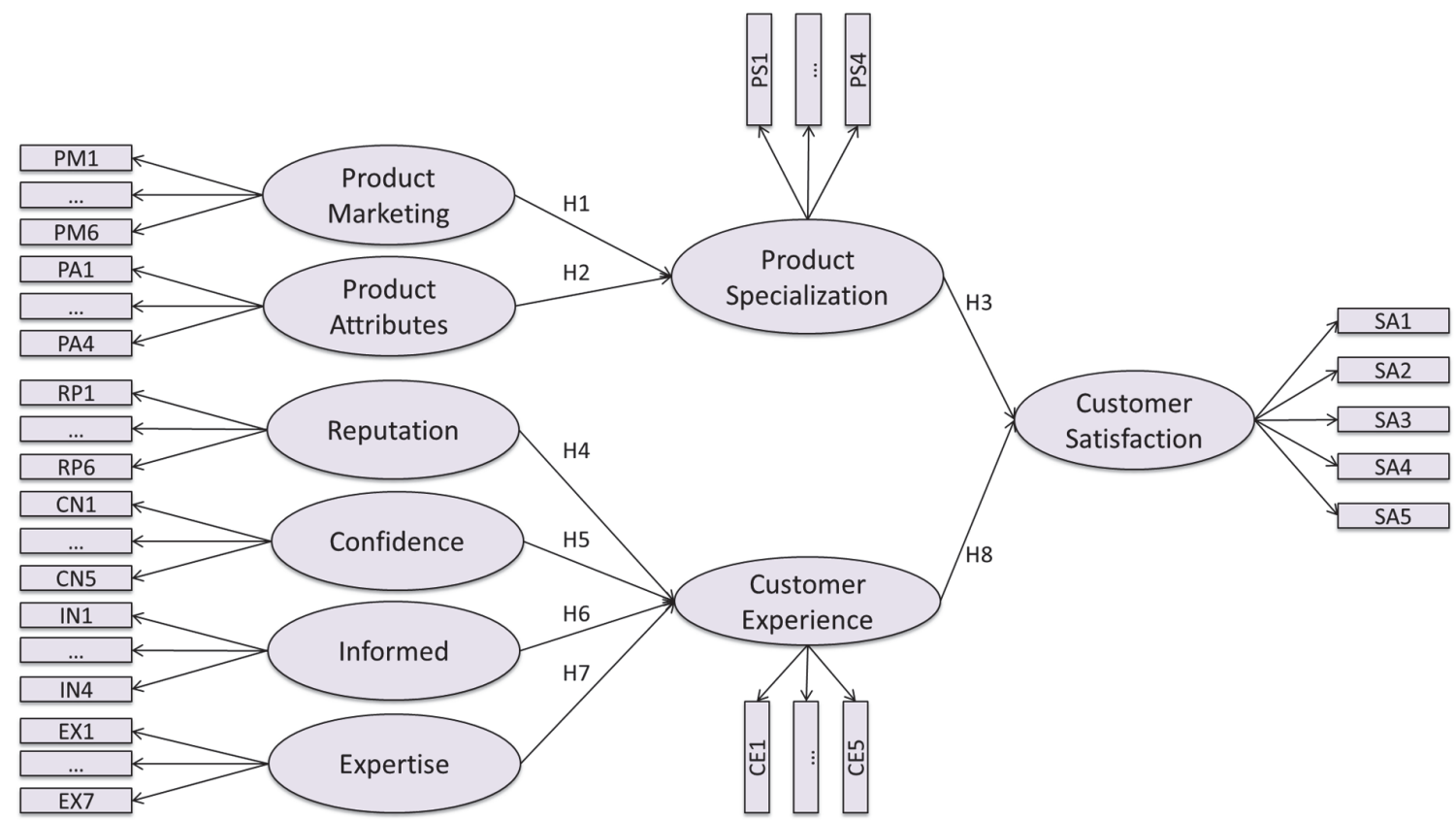

Fig. 2. Theoretical Model with Hypotheses and Observed Variables.

Step 3. The research instrument was created by the author. The format of the questionnaire was designed based on the Likert Scale measures. All item scales were based on 1 (Strongly Disagree), 2 (Disagree), 3 (Neutral), 4 (Agree) and 5 (Strongly Agree). The analysis method was based on Structural Equation Modeling. The questionnaire items were developed with simple wordings and sentence structures for the respondent's ease understanding. 
Step 4. Questionnaire validity was established by allowing peers to check for ease of readability and comprehension. Any difficulty of readability was rectified by simplifying the question. Comprehension was improved to ensure unambiguous understanding. All changes were made directly upon revision. This field test was done with the help of five colleagues.

Step 5. Questionnaire reliability was established by conducting a small-scale Cronbach's alpha test. This pilot test was done with the help of ten volunteer colleagues. Volunteers for this test were not used in the full-scale study.

\section{Results and Findings}

For the main study, a total of 250 respondents were targeted but only 210 respondents gave useable questionnaire. The sample size was determined by Cochran's formula (Cochran, 1977). The sample size is given by $n_{0}=\frac{Z_{\alpha}^{2} p(1-p)}{\alpha^{2}}$. Using $\alpha=0.05$, and $p=0.50, Z_{\alpha}=1.64, n_{o}=270$ units. For a finite population, the corrected formula is $n=\frac{n_{o}}{1+\frac{n_{0}-1}{N}}$. For

a finite target population of $N=1,000$, the corrected sample size $n=213$ units. Data collection was conducted through faceto-face interview over a period of four weeks. Respondents were assured of the confidentiality and security of their responses. Based on the Cochran's sample size formula, the sample size was 213. Although 300 questionnaires were issued, after eliminating incomplete or errorneous responses, only 210 questionnaires were usable. The breakdown of the respondents is available by gender, education, age and income.

\subsection{Gender}

Of the 210 respondents, 115 (54.76 percent) were male, 95 (45.24 percent) were female.

\subsection{Education}

Of the 210 respondents, 23 (10.95 percent) had a school certificate, 62 (29.52 percent) had a high school certificate, 80 (38.1 percent) had a university degree, 26 (12.38 percent) had a Masters' degree, and 19 (9.05 percent) had a PhD degree. See Fig. 3.
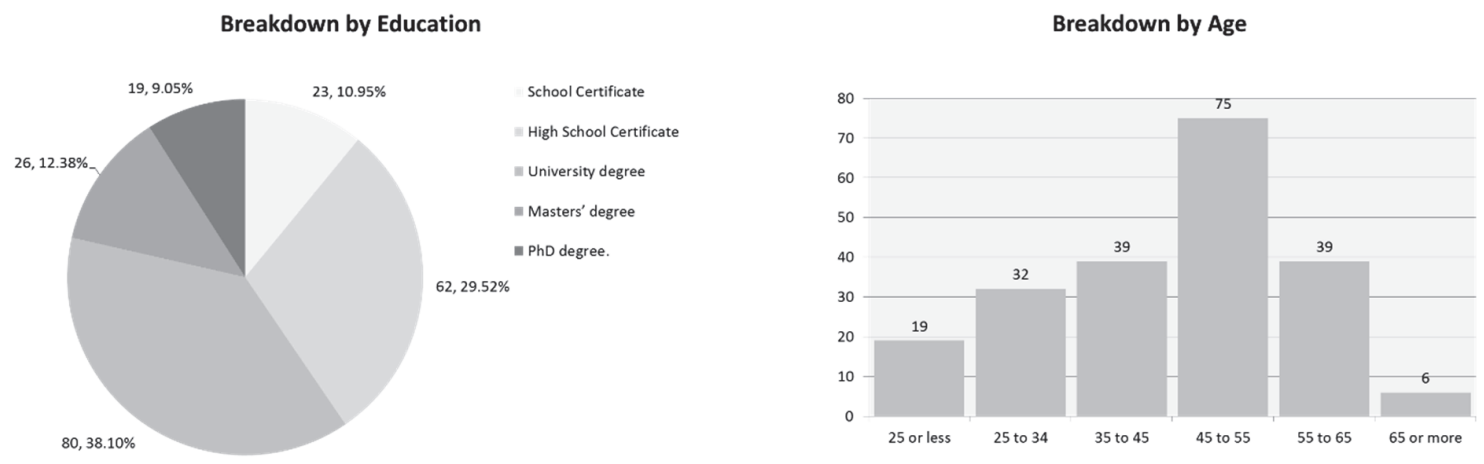

Fig. 3. Breakdown by Education.

Fig. 4. Breakdown by Age

\subsection{Age}

Of the 210 respondents, 19 (9.05 percent) were aged between 25 or less years, 32 (15.24 percent) were aged between 25 to 34 years, 39 (18.57 percent) were aged between 35 to 45 years, 75 (35.71 percent) were aged between 45 to 55 years, 39 (18.57 percent) were aged between 55 to 65years, and 6 (2.86 percent) were aged 65 or more years. See Fig. 4.

\subsection{Income}

Of the 210 respondents, 61 (29.05 percent) earned low income, 102 (48.57 percent) earned medium income, and 47 (22.38 percent) earned high income. See Fig. 5. 


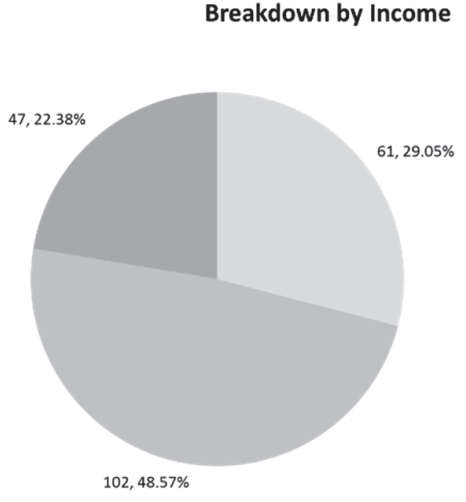

Fig. 5. Breakdown by Income

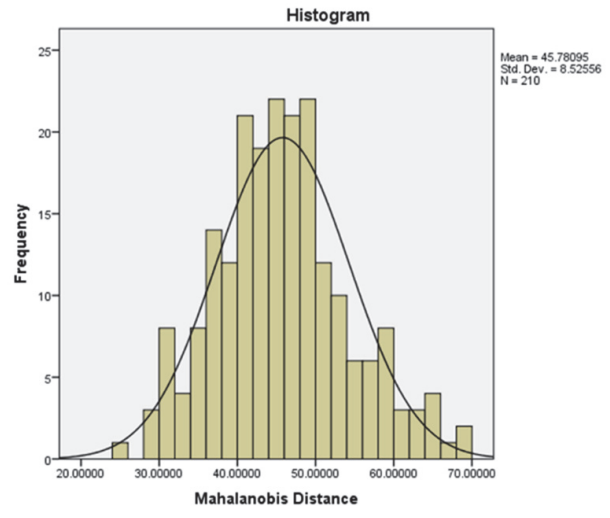

Fig. 6. Histogram of Mahalanobis Distance

\subsection{Data Analysis and Results}

The first step in data analysis was to look for the accuracy in data entry, missing values and erroneous data. A descriptive data analysis showed that the Skewness were well within an acceptable range of \pm 2 (Garson, 2012). All Kurtosis values were also within an acceptable range of \pm 2 (Garson, 2012). Next, the data was examined for outliers. A multivariate outlier detection was done using Mahalanobis Distance by fitting the observation number (independent variable) and all 46 items. Results showed that with $\alpha=0.001$, the critical Mahalanobis Distance, $D^{2}$ value was 93.168 based on ChiSquare.Inv $=(\alpha$, $v$ ) where $\alpha$ is the error level and $v$ is the degrees of freedom (Tabachnick \& Fidell, 2007). However, no outliers were found with a threshold value of alpha $=0.001$. A histogram of the Mahalanobis Distance is shown in Fig. 6 . Two tests of normality were conducted, i.e. Kolmogorov-Smirnov and Shapiro-Wilk tests. If the $p$-value was greater than the chosen alpha, e.g. $\alpha$ $=0.05$ then the null hypothesis that the data is normally distributed is retained. If the test statistic $p$-value was lesser than the chosen alpha, e.g. $\alpha=0.05$. then the null hypothesis that the data is normally distributed is rejected. The KolmogorovSmirnov tests of normality statistic is $W=0.051$ with $p=0.2$ and hence the data is not significantly different from a normal distribution. The Shapiro-Wilk tests of normality statistic is $W=0.988$ with $p=0.08$ and hence the data is not significantly different from a normal distribution. The Kaiser-Meyer-Olkin (KMO) is a measure of sampling adequacy of a dataset for factor analysis. The test measures sampling adequacy for a variable and is a measure of the proportion of variance among variables that might be due to common variance. The KMO varies between 0 and 1 . KMO values closer to 1 are good and the value of 0.5 is the suggested minimum. A measure of sampling adequacy, KMO, greater than 0.6 would suggest that the sample size was adequate (Tabachnick \& Fidell, 2007). Since the KMO is 0.93, the sample size was large enough for assessing the factor structure. The Bartlett's test of sphericity is a test for the null hypothesis that the correlation matrix has an identity matrix. An identity matrix is a matrix in which all of the diagonal elements are 1 and all off diagonal elements are 0 . Thus, the null hypothesis is that there is no statistically significant interrelationship between variables. If this test is significant, it would indicate that the variables are unrelated and therefore unsuitable for detecting structure. A test value lesser than some chosen alpha, e.g. $\alpha=0.05$ would suggest that at least 2 items were highly correlated, i.e. the alternative hypothesis that there may be a statistically significant interrelationship between the variables. The Bartlett's test of sphericity gave an approximate ChiSquare value of 9606, with degrees of freedom $(d f)=1035$ and $p=0$ suggesting that at least two items were highly correlated. Hence, factor analysis was considered as an appropriate technique for further data analysis. An Exploratory Factor Analysis consisting of 42 items was conducted based on the Extraction Method of Principal Components Analysis (PCA) and Kaizen rotation. The Rotation Method was Varimax with Kaiser Normalization which converged in seven iterations. The Varimax rotation is an orthogonal rotation that does not permit factors to be correlated.

The number of factors to retain can be determined by several methods (Maike, 2008). Since the analysis uses standardized items, each item has a variance of 1 and the total variance is equal to the number of items. IBM SPSS used a default eigenvalue $\geq 1$ to select the number of factors. This selection of factors using eigenvalues $\geq 1$ is the Kaiser criterion and is only a rule of thumb (Maike, 2008). The second option is by the scree plot. A scree plot shows the eigenvalues on the $y$ axis and the number of factors on the $x$-axis. The scree plot always displays a downward curve. The point where the slope of the curve clearly levels off is called the inflection or elbow and indicates the number of meaningful factors. The third option is the grouping of the rotated factors. Lastly, the researcher could select the number of factors for getting a reasonable proportion of variance explained. The Total Variance Explained is shown in Table . Factor 9 was included in the analysis since the this is indicated by the inflection in the scree plot of the eigenvalues shown in Fig. 7. Additionally, the factor grouping also suggested 9 factors evident from the grouping of items shown in Table. Thus, for the purpose of subsequent analysis, the first 9 factors were accepted for further analysis. These factors together explained 78.58 percent of the variance. 
Table 2

Total Variance Explained

\begin{tabular}{|c|c|c|c|c|c|c|}
\hline \multirow[b]{2}{*}{ Component } & \multicolumn{3}{|c|}{ Initial Eigenvalues } & \multicolumn{3}{|c|}{ Rotation Sums of Squared Loadings } \\
\hline & Total & $\%$ of Variance & Cumulative \% & Total & $\%$ of Variance & Cumulative $\%$ \\
\hline 1 & 15.528 & 33.756 & 33.756 & 6.383 & 13.875 & 13.875 \\
\hline 2 & 7.374 & 16.030 & 49.786 & 4.947 & 10.755 & 24.631 \\
\hline 3 & 2.981 & 6.480 & 56.267 & 4.910 & 10.674 & 35.304 \\
\hline 4 & 2.684 & 5.834 & 62.101 & 3.851 & 8.371 & 43.675 \\
\hline 5 & 2.402 & 5.221 & 67.322 & 3.807 & 8.276 & 51.952 \\
\hline 6 & 1.737 & 3.776 & 71.097 & 3.567 & 7.754 & 59.706 \\
\hline 7 & 1.612 & 3.504 & 74.602 & 3.226 & 7.013 & 66.719 \\
\hline 8 & 1.289 & 2.803 & 77.405 & 3.209 & 6.977 & 73.696 \\
\hline 9 & 1.107 & 2.407 & 79.812 & 2.814 & 6.116 & 79.812 \\
\hline 10 & .532 & 1.157 & 80.969 & & & \\
\hline$\ldots$ & & & & & & \\
\hline 46 & .038 & .082 & 100.000 & & & \\
\hline
\end{tabular}

Table 3

Factor Rotation, Extraction and Variance Inflation Factor.

\begin{tabular}{|c|c|c|c|c|c|c|c|c|c|c|c|}
\hline \multirow[b]{2}{*}{ Item } & \multicolumn{9}{|c|}{ Component Loading } & \multirow{2}{*}{$\begin{array}{c}\text { Communality } \\
\text { Extraction }\end{array}$} & \multirow{2}{*}{$\frac{\text { Collinearity }}{\text { VIF }}$} \\
\hline & 1 & 2 & 3 & 4 & 5 & 6 & 7 & 8 & 9 & & \\
\hline PM1 & -.003 & .842 & .076 & -.020 & .097 & .019 & .066 & .151 & .025 & .753 & 3.378 \\
\hline PM2 & .068 & .825 & .075 & -.003 & -.033 & .026 & .175 & .172 & .046 & .755 & 3.376 \\
\hline PM3 & -.083 & .808 & .048 & .015 & .012 & .006 & .155 & .232 & .036 & .743 & 3.384 \\
\hline PM4 & .044 & .815 & -.027 & .045 & .016 & .012 & .085 & .144 & .018 & .698 & 2.696 \\
\hline PM5 & -.049 & .843 & .068 & -.056 & .087 & .053 & .084 & .119 & .014 & .753 & 3.217 \\
\hline PM6 & .003 & .814 & -.047 & .099 & .048 & -.055 & .144 & .181 & -.046 & .735 & 3.146 \\
\hline PT1 & .033 & .224 & .015 & .032 & -.084 & -.023 & .822 & .215 & .026 & .783 & 3.292 \\
\hline PT2 & .051 & .184 & .012 & .078 & -.049 & -.078 & .824 & .169 & .043 & .760 & 2.759 \\
\hline PT3 & -.015 & .103 & .070 & -.004 & -.040 & -.054 & .818 & .217 & -.083 & .743 & 2.629 \\
\hline PT4 & -.021 & .175 & -.016 & -.010 & -.017 & .020 & .859 & .129 & .000 & .786 & 2.962 \\
\hline PS1 & .041 & .405 & .086 & -.003 & -.032 & .056 & .258 & .774 & -.057 & .847 & 5.035 \\
\hline PS2 & -.068 & .409 & .106 & -.027 & -.053 & .059 & .256 & .774 & -.016 & .855 & 5.140 \\
\hline PS3 & -.008 & .384 & .034 & -.056 & .001 & .003 & .304 & .768 & .069 & .839 & 4.575 \\
\hline PS4 & -.015 & .339 & .046 & -.065 & -.022 & .016 & .255 & .807 & .037 & .840 & 4.083 \\
\hline RP1 & .828 & -.061 & .177 & .215 & .183 & .041 & -.022 & .021 & -.001 & .803 & 4.039 \\
\hline RP2 & .821 & -.057 & .162 & .108 & .207 & .117 & .018 & -.008 & .035 & .773 & 3.595 \\
\hline RP3 & .812 & .042 & .128 & .103 & .212 & .129 & .025 & -.028 & .098 & .760 & 3.234 \\
\hline RP4 & .774 & -.050 & .201 & .183 & .209 & .093 & -.033 & -.049 & .160 & .757 & 3.658 \\
\hline RP5 & .797 & .027 & -.008 & .203 & .233 & .117 & .036 & .039 & .162 & .774 & 3.367 \\
\hline RP6 & .824 & .050 & .147 & .188 & .105 & .092 & .028 & -.016 & .089 & .766 & 3.455 \\
\hline CN1 & .243 & .073 & .199 & .758 & .186 & .219 & .009 & -.042 & .009 & .763 & 3.879 \\
\hline $\mathrm{CN} 2$ & .195 & .023 & .158 & .770 & .202 & .241 & -.008 & .021 & .108 & .767 & 3.739 \\
\hline $\mathrm{CN} 3$ & .202 & .015 & .220 & .793 & .225 & .122 & .018 & -.078 & .033 & .791 & 3.774 \\
\hline $\mathrm{CN} 4$ & .141 & .005 & .116 & .769 & .184 & .284 & .048 & .042 & .144 & .764 & 3.167 \\
\hline CN5 & .292 & -.046 & .160 & .783 & .090 & .185 & .050 & -.086 & .106 & .789 & 3.887 \\
\hline IN1 & .142 & .021 & .172 & .265 & .060 & .853 & -.042 & .003 & .119 & .867 & 5.483 \\
\hline IN2 & .129 & -.013 & .107 & .190 & .148 & .873 & -.004 & .061 & -.002 & .852 & 4.388 \\
\hline IN3 & .107 & -.008 & .097 & .241 & .107 & .881 & -.029 & .024 & .099 & .878 & 5.672 \\
\hline IN4 & .137 & .066 & .162 & .174 & .139 & .872 & -.074 & .012 & .041 & .867 & 5.415 \\
\hline EX2 & .323 & .046 & .361 & .168 & .380 & .168 & .038 & .013 & .706 & .938 & 9.486 \\
\hline EX6 & .292 & .059 & .354 & .227 & .375 & .138 & -.051 & .015 & .717 & .943 & 10.171 \\
\hline EX7 & .315 & .050 & .403 & .225 & .341 & .155 & -.015 & .025 & .690 & .933 & 9.307 \\
\hline CE1 & .304 & .022 & .153 & .146 & .724 & .106 & -.088 & .001 & .128 & .697 & 2.775 \\
\hline CE2 & .203 & .086 & .194 & .189 & .703 & .139 & -.101 & .049 & .167 & .676 & 2.756 \\
\hline CE3 & .360 & .100 & .207 & .203 & .710 & .036 & -.057 & -.039 & .040 & .736 & 3.121 \\
\hline CE4 & .252 & .020 & .245 & .178 & .761 & .079 & -.057 & .018 & .117 & .759 & 3.281 \\
\hline CE5 & .177 & .043 & .176 & .175 & .748 & .180 & .042 & -.139 & .137 & .726 & 2.793 \\
\hline SA1 & .135 & -.025 & .836 & .081 & .128 & .096 & .003 & .082 & .085 & .763 & 2.935 \\
\hline SA2 & .110 & .120 & .797 & .174 & .132 & .145 & .081 & -.031 & .064 & .742 & 2.823 \\
\hline SA3 & .237 & .092 & .750 & .151 & .175 & .135 & .068 & .118 & .133 & .735 & 3.329 \\
\hline SA4 & .133 & -.020 & .794 & .151 & .202 & .130 & -.014 & -.001 & .104 & .741 & 3.337 \\
\hline SA5 & .136 & .057 & .794 & .188 & .199 & .053 & -.021 & .071 & .139 & .754 & 3.267 \\
\hline
\end{tabular}




\section{Scree Plot of Eigenvalues}

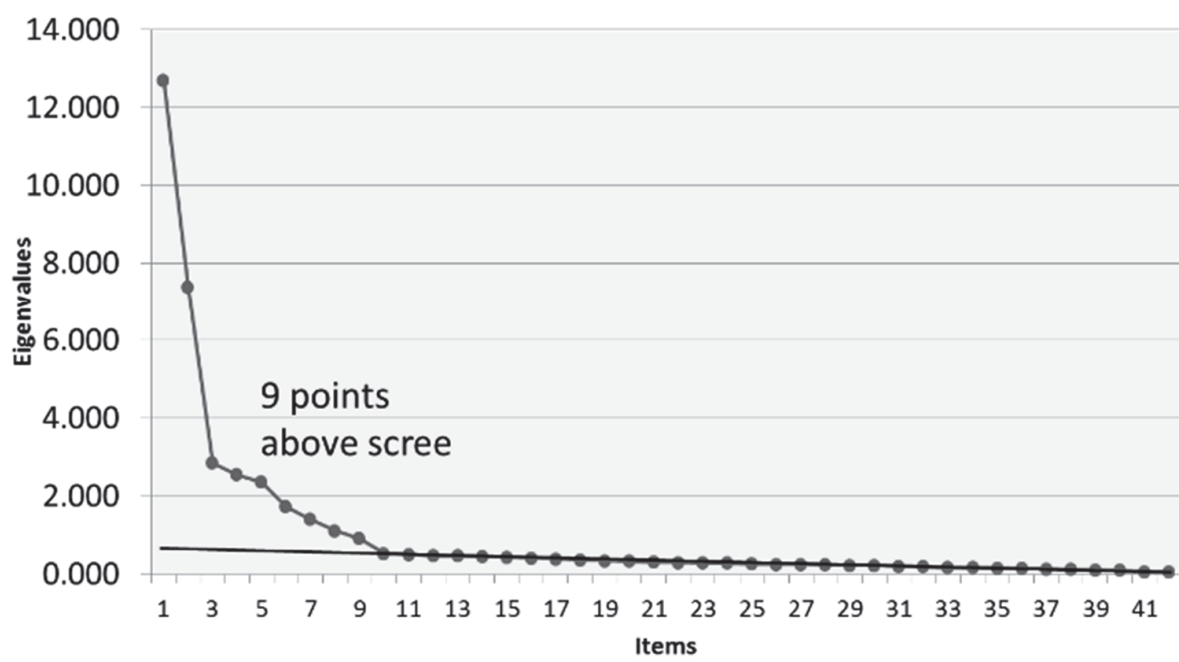

Fig. 7. Scree Plot of Items.

The communalities of all items were also greater than 0.6 (Hair, Hult, Ringle, \& Sarstedt, 2014). This is the proportion of variance of each item that can be explained by the underlying factor (latent variable). Multicollinearity is the extent to which independent variables (items) are correlated. Multicollinearity exists when an item is highly correlated with another item or a linear combination of other items (Daoud, 2017). High correlation among items reduces predictability of the regression equation. This results in unreliable regression coefficients and misleading significance of items. Therefore, it is necessary to check for multicollinearity in the items.

Multicollinearity was measured by the Variance Inflation Factor (VIF). It is a measure of the multicollinearity between the items in the data. VIF is calculated as $V I F=\frac{1}{1-r_{k}^{2}}$. It is a potential problem when VIF $>5$ and a serious problem when VIF $>10$ (Hair, Black, Babin, \& Anderson, 2014). Four items that had VIF > 10 (EX1, EX3, EX4, EX5) were dropped from the study. For the remaining 42 items shown in Table, there is no concern for large VIF and these items were retained.

A Cronbach's alpha analysis also showed that all constructs were highly reliable. Cronbach's alpha is a measure of internal consistency of how closely related a set of items are as a group. For a construct with $K$ items, $\sigma_{Y}$ is the variance of each item, $\sigma_{X}$ is the variance of all the items in the construct, and Cronbach's alpha $\left(\alpha_{C}\right)$ is given as:

$\alpha_{C}=\frac{K}{K-1}\left(1-\frac{\sum_{i=1}^{K} \sigma_{Y_{i}}^{2}}{\sigma_{X}^{2}}\right)$

High Cronbach's alpha coefficients suggest that there is high internal consistency. A reliability coefficient of 0.70 or higher is considered acceptable in most studies (Hair, Black, Babin, \& Anderson, 2014). See Table 4.

Table 4

Internal Consistency

\begin{tabular}{cccc}
\hline No & Construct & No. Items & Cronbach's Alpha \\
\hline 1 & PM & 6 & 0.924 \\
2 & PT & 4 & 0.894 \\
3 & PS & 4 & 0.937 \\
4 & RP & 6 & 0.936 \\
5 & CN & 5 & 0.921 \\
6 & IN & 4 & 0.945 \\
7 & EX & 3 & 0.969 \\
8 & CE & 5 & 0.894 \\
9 & SA & 5 & 0.910 \\
\hline
\end{tabular}


To test for construct validity, two types of validities were tested, namely, convergent validity (CV) and divergent validity (DV). Convergent validity ensures that items within a factor do indeed converge to measure the same factor. This was done by calculating the Average Variance Extracted (AVE) and the Composite Reliability (CR). The AVE was calculated from the standardized estimates $\left(\lambda_{i}\right)$ of the items within the factor. $A V E=\frac{\sum_{i=1}^{n} \lambda_{i}^{2}}{n}$ and $C R=\frac{\left(\sum_{i=1}^{n} \lambda_{i}\right)^{2}}{\left(\sum_{i=1}^{n} \lambda_{i}\right)^{2}+\left(\sum_{c=1}^{n} 1-\lambda_{i}^{2}\right)}$.

.Convergent validity was established if AVE $>0.5$ and CR $>0.7$ (Hair, Hult, Ringle, \& Sarstedt, 2014). From Table, convergent validity was established for all factors. Discriminant validity is the extent a construct is different from another construct. It also determines the differences between overlapping constructs. Discriminant validity was determined by the Fornell-Larker criteria. This was done by evaluating cross loading of indicators and ensuring that all inter-correlations between the constructs were smaller than the square root of the AVE for that construct (Fornell \& Larcker, 1981). The square root of the AVE is shown in the main diagonal in Table. Hence, a construct has divergent validity if all the cross correlations were smaller than the square root of the AVG. The results are shown collectively in Table 6.

Table 5

Cross Loading Constructs

\begin{tabular}{|c|c|c|c|c|c|c|c|c|c|}
\hline & PM & PT & PS & RP & $\mathrm{CN}$ & IN & EX & $\mathrm{CE}$ & SA \\
\hline PM & 0.82 & 0.41 & 0.66 & 0.01 & 0.05 & 0.05 & 0.11 & 0.11 & 0.13 \\
\hline PT & 0.41 & 0.82 & 0.59 & 0.01 & 0.04 & -0.06 & 0.00 & -0.10 & 0.07 \\
\hline PS & 0.66 & 0.59 & 0.89 & -0.02 & -0.04 & 0.05 & 0.00 & -0.03 & 0.15 \\
\hline RP & 0.01 & 0.01 & -0.02 & 0.84 & 0.55 & 0.35 & 0.00 & 0.64 & 0.45 \\
\hline $\mathrm{CN}$ & 0.05 & 0.04 & -0.04 & 0.55 & 0.84 & 0.56 & 0.00 & 0.58 & 0.50 \\
\hline IN & 0.05 & -0.06 & 0.05 & 0.35 & 0.56 & 0.90 & 0.00 & 0.39 & 0.38 \\
\hline $\mathrm{EX}$ & 0.11 & 0.00 & 0.05 & 0.60 & 0.56 & 0.42 & 0.96 & 0.74 & 0.68 \\
\hline $\mathrm{CE}$ & 0.11 & -0.10 & -0.03 & 0.64 & 0.58 & 0.39 & 0.00 & 0.79 & 0.57 \\
\hline SA & 0.13 & 0.07 & 0.15 & 0.45 & 0.50 & 0.38 & 0.00 & 0.57 & 0.82 \\
\hline DV & Yes & Yes & Yes & Yes & Yes & Yes & Yes & Yes & Yes \\
\hline
\end{tabular}

Table 6

Convergent and Divergent Validity

\begin{tabular}{lrrrrrrrrr}
\hline & PM & PT & PS & RP & CN & IN & EX & CE & SA \\
\hline Items & 6 & 4 & 4 & 6 & 5 & 4 & 3 & 5 & 5 \\
C $\alpha$ & 0.924 & 0.894 & 0.937 & 0.936 & 0.921 & 0.945 & 0.969 & 0.894 & 0.910 \\
AVE & 0.671 & 0.680 & 0.788 & 0.709 & 0.700 & 0.812 & 0.912 & 0.621 & 0.670 \\
CR & 0.987 & 0.977 & 0.984 & 0.990 & 0.983 & 0.986 & 0.989 & 0.975 & 0.980 \\
CV & Yes & Yes & Yes & Yes & Yes & Yes & Yes & Yes & Yes \\
DV & Yes & Yes & Yes & Yes & Yes & Yes & Yes & Yes & Yes \\
SEM & Yes & Yes & Yes & Yes & Yes & Yes & Yes & Yes & Yes \\
\hline
\end{tabular}

Since the convergent validity (CV in Table 6) and divergent validity (DV in Table ) met the criteria above, all nine constructs were admitted into the Structural Equation Model (SEM in Table 6) shown in Fig. 8. A Confirmatory Factor Analysis was then conducted using IBM SPSS-AMOS version 21.

Table 7

Estimates of SEM

\begin{tabular}{cccccccc}
\multicolumn{2}{c}{ Relationship } & & Estimate & $\begin{array}{c}\text { Standard } \\
\text { Error }\end{array}$ & Critical Ratio & P-Value & Decision \\
\hline PS & $\leftarrow$ & PM & 0.593 & 0.08 & 7.77 & 0.00 & Significant \\
PS & $\leftarrow$ & PT & 0.421 & 0.07 & 6.06 & 0.00 & Significant \\
CE & $\leftarrow$ & RP & 0.271 & 0.08 & 3.44 & 0.00 & Significant \\
CE & $\leftarrow$ & CN & 0.206 & 0.09 & 2.43 & 0.02 & Significant \\
CE & $\leftarrow$ & IN & $\mathbf{0 . 0 0 8}$ & $\mathbf{0 . 0 5}$ & $\mathbf{0 . 1 5}$ & $\mathbf{0 . 8 8}$ & Not Significant \\
CE & $\leftarrow$ & EX & 0.407 & 0.06 & 7.32 & 0.00 & Significant \\
SA & $\leftarrow$ & PS & 0.110 & 0.04 & 2.59 & 0.01 & Significant \\
SA & $\leftarrow$ & CE & 0.461 & 0.06 & 8.43 & 0.00 & Significant \\
\hline
\end{tabular}




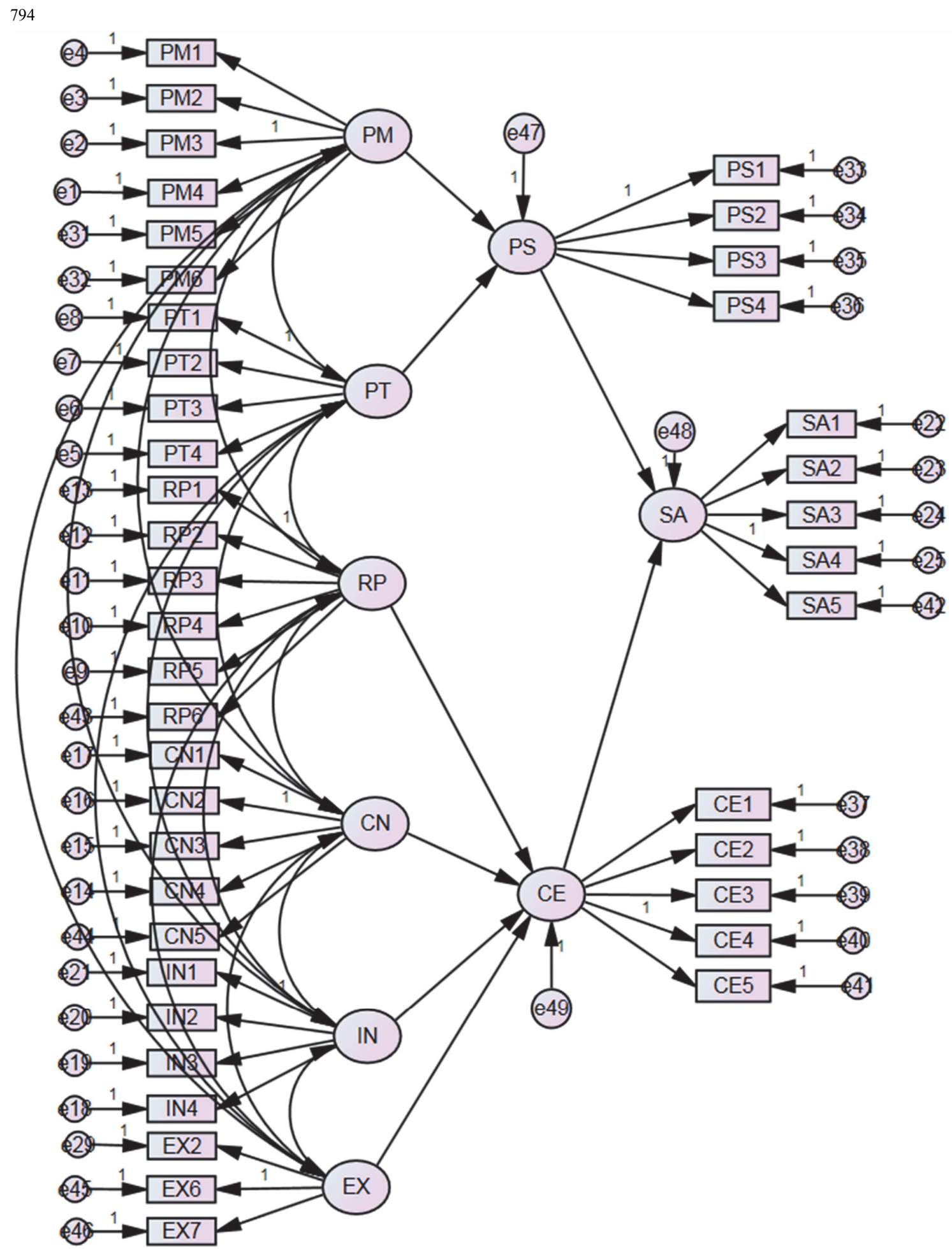

Fig. 8. Structural Model

Particular care was taken to ensure that the regression weights were constrained, i.e. highest regression weight for each construct was given a parameter value of 1 . Subsequently, an analysis of the estimates for the structural model showed results as in Table 7 . Note that all regression estimates are significant at $\alpha=0.05$, except for the construct IN.

\subsection{Reduced Model}

Clearly the construct IN did not contribute to the overall model. This construct was not significant, and hence the construct was dropped from the model to form the reduced model as shown in Fig. 9. 


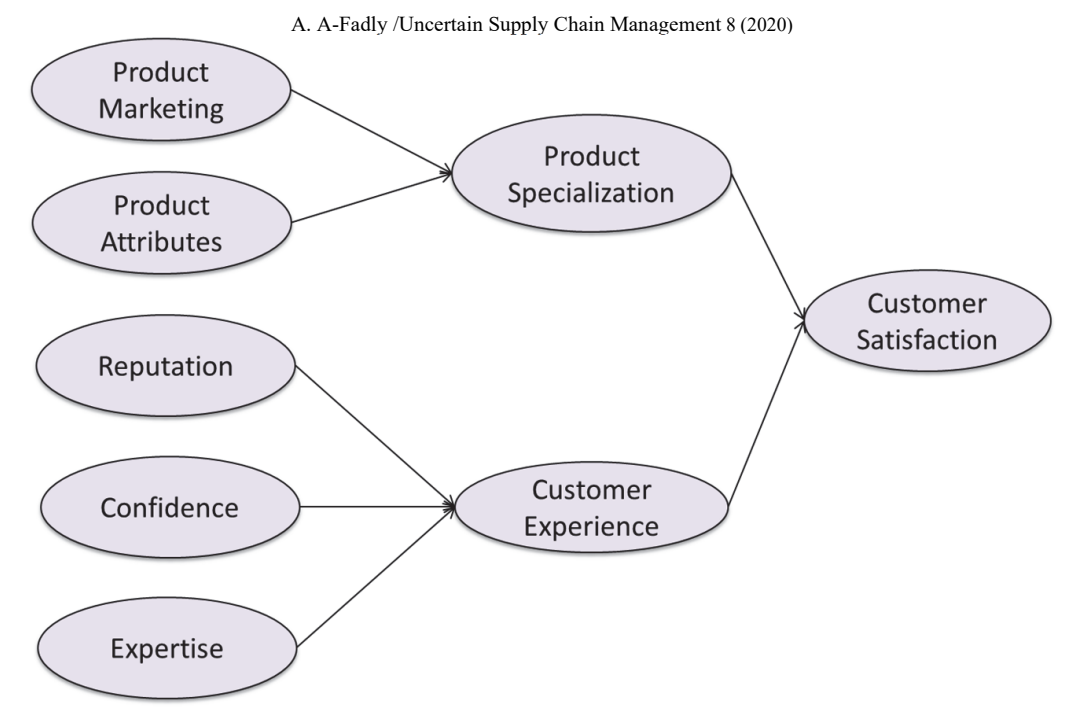

Fig. 9. Reduced Structural Model.

For this reduced structural model, all construct estimates were found to be significant as shown in Table 8 .

Table 8

Estimates of SEM for Reduced Model

\begin{tabular}{|c|c|c|c|c|c|c|c|}
\hline \multicolumn{3}{|c|}{ Relationship } & \multirow{2}{*}{$\begin{array}{r}\text { Estimate } \\
0.592\end{array}$} & \multirow{2}{*}{$\begin{array}{c}\begin{array}{c}\text { Standard } \\
\text { Error }\end{array} \\
0.08\end{array}$} & \multirow{2}{*}{$\begin{array}{c}\text { Critical Ratio } \\
7.76\end{array}$} & \multirow{2}{*}{$\frac{\text { P-Value }}{0.00}$} & \multirow{2}{*}{$\begin{array}{c}\text { Decision } \\
\text { Significant }\end{array}$} \\
\hline PS & $\leftarrow$ & PM & & & & & \\
\hline PS & $\leftarrow$ & PT & 0.422 & 0.07 & 6.08 & 0.00 & Significant \\
\hline $\mathrm{CE}$ & $\leftarrow$ & $\mathrm{RP}$ & 0.271 & 0.08 & 3.43 & 0.00 & Significant \\
\hline $\mathrm{CE}$ & $\leftarrow$ & $\mathrm{CN}$ & 0.213 & 0.08 & 2.80 & 0.01 & Significant \\
\hline $\mathrm{CE}$ & $\leftarrow$ & $\mathrm{EX}$ & 0.408 & 0.06 & 7.39 & 0.00 & Significant \\
\hline SA & $\leftarrow$ & PS & 0.110 & 0.04 & 2.60 & 0.01 & Significant \\
\hline SA & $\leftarrow$ & $\mathrm{CE}$ & 0.461 & 0.06 & 8.43 & 0.00 & Significant \\
\hline
\end{tabular}

Table 9 shows the fit indices for the full model and reduced model. Fig. 10 shows the same data in a graphical form. The reduced model also suggests that the model could not be improved further as shown in Fig. 10. Therefore, the model invariance suggested that the reduced model was the best trade-off between model fit and model complexity. Note that the reduced model has excellent fit and only fails PGFI by a marginal effect. An explanation of the indices is given below.

Table 9

Comparison of Model Fit Indices: Full and Reduced Model

\begin{tabular}{|c|c|c|c|c|c|}
\hline & Threshold & Full Model & Test & Reduced Model & Test \\
\hline CMIN/DF < & 5.00 & 1.173 & Pass & 1.139 & Pass \\
\hline RMSEA < & 0.08 & 0.029 & Pass & 0.026 & Pass \\
\hline $\mathrm{RMR}<$ & 0.05 & 0.049 & Pass & 0.048 & Pass \\
\hline GFI > & 0.80 & 0.836 & Pass & 0.852 & Pass \\
\hline AGFI > & 0.80 & 0.814 & Pass & 0.831 & Pass \\
\hline PGFI > & 0.80 & 0.737 & Fail & 0.745 & Fail \\
\hline NFI $>$ & 0.80 & 0.886 & Pass & 0.896 & Pass \\
\hline RFI > & 0.80 & 0.877 & Pass & 0.888 & Pass \\
\hline IFI $>$ & 0.80 & 0.981 & Pass & 0.986 & Pass \\
\hline TLI > & 0.80 & 0.980 & Pass & 0.985 & Pass \\
\hline $\mathrm{CFI}>$ & 0.80 & 0.981 & Pass & 0.986 & Pass \\
\hline PRATIO > & 0.80 & 0.925 & Pass & 0.922 & Pass \\
\hline PNFI > & 0.80 & 0.819 & Pass & 0.826 & Pass \\
\hline PCFI > & 0.80 & 0.907 & Pass & 0.909 & Pass \\
\hline
\end{tabular}




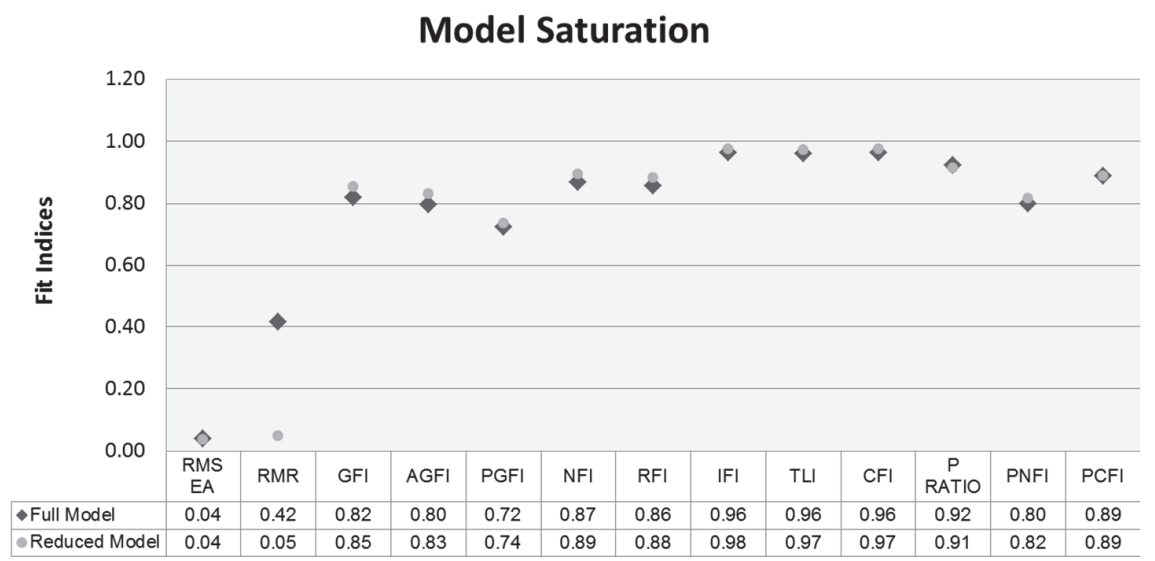

Fig. 10. Model Fit Indices - Saturation

The CMIN/DF assesses the magnitude of discrepancy between the sample and fitted covariance matrices. The CMIN/DF should be below 5.0 (Hooper, Coughlan, \& Mullen, 2008). The RMSEA is the root mean square error of approximation. It is regarded the most informative fit index due to its sensitivity to the number of parameters in the model. An RMSEA fit of 0.08 or less is recommended (Tabachnick \& Fidell, 2007). The RMR is the root mean residual and is the square root of the difference between the residuals of the sample covariance matrix and the hypothesized covariance model. The recommended value is less than 0.08 (Hooper, Coughlan, \& Mullen, 2008). The GFI is the goodness-of-fit statistic that calculates the proportion of variance due to the estimated population covariance. Its recommended value $>0.80$ (Tabachnick \& Fidell, 2007). The AGFI is the adjusted goodness-of-fit statistic that calculates the proportion of variance with an adjustment for the degrees of freedom in a model. Its recommended value $>0.80$ (Tabachnick \& Fidell, 2007). The PGFI is the parsimonious goodness-of-fit statistic adjusted for loss of degrees of freedom based on the GFI. Its recommended value $>0.80$ (Tabachnick \& Fidell, 2007). The NFI is the normed fit index that assesses the model by comparing the chisquare of the model to the chi-square of the null model. Its recommended value is $>0.80$ (Bentler \& Bonnet, 1987). The RFI is the relative fit index compares improvements in the tested model against. the independent model based on fixing all inter-factor covariance to zero and only calculating variances. The recommended value is $>0.80$ (Hooper, Coughlan, \& Mullen, 2008). The IFI is the incremental fit index also called Bollen's fit index and it is relatively unaffected by sample size. Its recommended value is $>0.80$ (Hooper, Coughlan, \& Mullen, 2008). The TLI is the Tucker-Lewis index with rectifies the NFI for its sensitivity to sample size less than 200 and also that it favours simpler models. Its recommended value is $>0.80$ (Mulaik \& Milsap, 2000). The CFI is the comparative fit index that takes account of sample size and performs well even for small sample size. Its recommended value is $>0.80$ (Tabachnick \& Fidell, 2007). The P ratio is the parsimony ratio which attempts to compensate for the complexity of models. When NFI and CFI are multiplied by this ratio the reduced ratio is called PNFI and PCFI. Its recommended value is $>0.80$ (Mulaik \& Milsap, 2000). The PNFI is the parsimonious normed fit index statistic adjusted for loss of degrees of freedom based on the NFI. Its recommended value $>0.80$ (Tabachnick \& Fidell, 2007). The PCFI is the parsimonious comparative fit index statistic adjusted for loss of degrees of freedom based on the CFI. Its recommended value $>0.80$ (Tabachnick \& Fidell, 2007).

\section{Discussion and Recommendations}

Product marketing (H1) is supported. This would imply that product marketing helped to develop relationship and differentiated their products and service. They were keen to know customer perceptions of their products to emphasize on delivering the "right" quality and responding to customer needs by emphasizing the benefits of their products.

Product attributes (H2) is supported. This would imply that range of brands helps customers to make better choices with increased attractiveness with product features that are important to customers with services that meet the customer's requirements.

Product specialization (H3) is supported. This would imply that specialized features attract more customers by offering "specialized" services by providing unique services that focus on diverse segments of customers.

The data shows reputation (H4) is supported. This would imply that customers need to see a good reputation of the company in the market. This is underlined by the fact that customers do not choose the construction company on price alone but represent their own brand well. Customers perceive that the offer of company that they chose has the best quality and is superior to the competition. 
Confidence (H5) is supported. This suggests that the customer is confident in the construction company's expertise. They receive independent advice on which product or service best suits the customer. Dealing with the construction company is easy when the customer deals with the same forms and same people in the companies.

Informed (H6) is not supported and its contribution was not significant.

Expertise (H7) is supported. This implied that expertise was perceived to be dealing with skilled people who deliver good customer experience. This built a personal relationship with the people at these companies when customers were offered "specialized" services. Their facilities were designed to fulfil the customer's needs better than their competitors. Their online facilities were designed to be as efficient as possible.

Relationship (H8) is supported. Customers stay with their construction companies because they were recognized and knew exactly what the customer wanted. The customer was confident that their needs would be looked after when their service was needed and to deal with the problems when something went wrong.

\subsection{Theoretical Contribution and Implication}

This research culminated in two important contributions. First, the construction industry benefits with an exposition of what factors within the product specialization are key to business growth. Second, customers benefit from sharing their perceptions directly with the management of the construction industry particularly in terms of what factors were vital for great customer experience. Hence, the aggregate responses through statistical analyses are vital to the construction companies. Altogether, construction companies will be able to plan better customer experience policies to enhance their competitive position, locally and globally.

\subsection{Implications for Practice}

Based on the first contribution above, construction companies particularly those that participated in this study can bring a company-wide staff realization of what factors are important for customer experience leading to delighted customers. Staff need to be given training on customer focus based on the customer's perception of what is delightful to customer experience. Any kind of management imposed "customer requirement" not based on facts should be deliberated and discarded in favour of the findings in this paper.

Based on the second contribution above, staff themselves should form teams that work towards delivering customer requirements as identified by the study. The practical implication of this would be that staff deliver services that are built around established customer requirements and not merely what is believed to be customer requirements. Such a strategy is more likely to provide a favourable customer experience leading to customer satisfaction and ultimately to better business.

\subsection{Limitations and Future Research Directions}

One limitation of study was that, although 300 respondents were targeted, only 213 respondents participated in the study. A further 3 respondent data was discarded as incorrect or incomplete and could not be used in the data analysis. Future studies could reach out to a much larger respondent base.

As for future research, one aspect that need to be considered is the total number of questionnaire items. The 46 questionnaire items appeared rather too many. In a few cases of respondents, the time spent on the questionnaire seemed to be too long with over 45 minutes. The large number of questionnaire items was due to the interest of achieving higher reliability of responses by having up to seven questionnaire items in some constructs. In future research, the number of questionnaire items within a construct could be reduced to at most four.

\section{Conclusion}

This study is a novel empirical accomplished on the effect of the product element of the marketing mix on the customer experience in the construction companies. Structural Equation Modelling has been used as a primary tool to assess causal structures. The method was very useful to identify factors that contributed, and factors that were insignificant, to the overall objective of the study. It was concluded that product marketing and product attributes perceived as product specialization was vital to customer satisfaction. Construction companies should take heed of these aspects which are perceived to be important to the customer. Similarly, reputation, confidence and expertise of the construction companies were perceived to be important to forge a close customer experience with the customer. Therefore, construction companies should endeavour to inculcate these perceptions into their company culture. Both product specialization and customer experience with the customer are vital to customer satisfaction. 


\section{References}

Al-Debi, H., \& Al-waely, D. F. (2015). The Effect of Services Marketing Mix Dimensions on Attracting Customers and Retaining Them: the Case of Jordanian Insurance Companies. International Journal of Marketing Studies, 7(5), 132146.

Awan, M. Y., Arshad, M. I., \& Awan, M. M. (2015). Construction Quality Perception of Construction Professionals Construction Quality Perception of Construction Professionals in Pakistan. European Journal of Business and Management, 83-94.

Bentler, P. M., \& Bonnet, D. G. (1987). Significance tests and goodness of fit in the analysis of covariance structures. Psychological Bulletine, 88, 588-606.

Bueno, E. V., Weber, T. B., Bomfim, E. L., \& Kato, H. T. (2019). Measuring customer experience in service: A systematic review. The Service Industries Journal, 1-20.

Cochran, W. G. (1977). Sampling Techniques, 3rd Edition. New York: John Wiley.

Daoud, J. I. (2017). Multicollinearity and Regression Analysis. Journal of Physics: Conference Series.

Dudovskiy, J. (2012, June 7). Customer Expectations in Service Industry. Retrieved December 9, 2016, from www.researchmethodology.net/customer-expectations-in-service-industry/

Fatma, S. (2014). Antecedents and Consequences of Customer Experience Management- A Literature Review and Research Agenda. International Journal of Business and Commerce, 366), 32-49.

Fornell, C., \& Larcker, D. F. (1981). Evaluating structural equation models with unobservable variables and measurement error. Journal of Marketing Research, 39-50.

Garson, G. D. (2012). Testing Statistical Assumptions. North Carolina: Statistical Associates Publishing.

Hair, J. F., Black, W. C., Babin, B. J., \& Anderson, R. E. (2014). Multivariate Data Analysis. Essen: Pearson New International Edition.

Hair, J., Hult, G. T., Ringle, C., \& Sarstedt, M. (2014). A Primer on Partial Least Squares Structural Equation Modeling (PLS-SEM). Los Angeles: SAGE Publications, Incorporated.

Hooper, D., Coughlan, J., \& Mullen, M. R. (2008). Structural equation modelling: Guidelines for determining model fit. The Electronic Journal of Business Research Methods, 6(1), 53-60.

Hu, L., \& Bentler, P. M. (1999). Structural Equation Modeling using AMOS: An Introduction. Retrieved from Structural Equation Modeling: https://doi.org/10.2307/1130298

Jarkas, A., \& Radosavljevic, A. M. (2012). Motivational factors impacting the productivity of construction master craftsmen in Kuwait. Journal of Management in Engineering, 29(4), 446-454.

Lemon, K. N., \& Verhoef, P. C. (2016). Understanding customer experience throughout the customer journey. Journal of marketing, 80(6), 69-96..

Lin, C.-H. (2011). A study on the relations between the brand image and customer satisfaction in catering businesses. African Journal of Business Management, 5(18), 7732-7739.

Mahmood, M., Sebt, M. H., \& Davoudpour, H. (2017). Characteristics of the construction industry from the marketing viewpoint: Challenges and solutions. Civil Engineering Journal, 3(9), 701-714.

Maike, R. (2008). Factor Analysis: A Short Introduction, Part 4-How many factors should I find? Retrieved January 10 , 2020, from The Analysis Factor: https:/www.theanalysisfactor.com/factor-analysis-how-many-factors/

Marketing Research Reports. (2016). Construction in Kuwait-Key trends and opportunities to 2017. Retrieved December 10, 2016, from Marketing Research Reports Inc.: https://new.pitchengine.com/pitches/8ab2a1b0-70da-45fa-ba15$175 \mathrm{c} 14034698$

Mokhtariani, M., Sebt, M. H., \& Davoudpour, H. (2017). Construction marketing: Developing a reference framework. Advances in Civil Engineering, 2017.

Mulaik, S. A., \& Milsap, R. E. (2000). Doing the Four-Step. Retrieved from Structural Equation Modelling: https://doi.org/10.1207/S15328007SEM0701

Radhakrishna, R. B. (2007). Tips for Developing and Testing Questionnaires/Instruments. Journal of Extension.

Sheng, M. L., \& Thompson, S. H. (2012). Product attributes and brand equity in the mobile domain: The mediating role of customer experience. International Journal of Information Management, 32(2), 139-146.

Tabachnick, B. G., \& Fidell, L. S. (2007). Using multivariate statistics (5th ed.). Allyn \& Bacon/Pearson Education.

Timetric. (2017, January 3). Timetric Construction Reports. Retrieved January 30, 2018, from https://timetric.com/research/report/cn0225mr--construction-in-kuwait-key-trends and-opportunities-to-2018/

Tsai, Y.-C., Chang, H.-C., \& Ho, K.-C. (2015). A Study of the Relationship among Brand Experiences, Self-Concept Congruence, Customer Satisfaction, and Brand Preference. Contemporary Management Research, 11(2), 97-116.

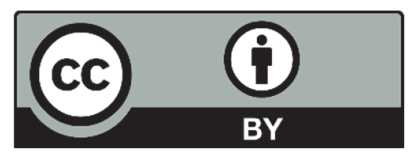

(C) 2020 by the authors; licensee Growing Science, Canada. This is an open access article distributed under the terms and conditions of the Creative Commons Attribution (CC-BY) license (http://creativecommons.org/licenses/by/4.0/). 